\title{
Research progress on thermal protection materials and structures of hypersonic vehicles *
}

\author{
YANG Ya-zheng (杨亚政 $)^{1,2}$ ，YANG Jia-ling (杨嘉陵 $)^{1} ，$ FANG Dai-ning (方岱宁 $)^{3}$ \\ (1. School of Aeronautic Science and Technology, Beijing University of Aeronautics and \\ Astronautics, Beijing 100083, P. R. China; \\ 2. Institute of Mechanics, Chinese Academy of Sciences, Beijing 100080, P. R. China;
} 3. Department of Engineering Mechanics, Tsinghua University, Beijing 100084, P. R. China)

(Communicated by MENG Qing-guo)

\begin{abstract}
Hypersonic vehicles represent future trends of military equipments and play an important role in future war. Thermal protection materials and structures, which 万方数腒ate to the safety of hypersonic vehicles, are one of the most key techniques in design and manufacture of hypersonic vehicles. Among these materials and structures, such as metallic temperature protection structure, the temperature ceramics and carbon/carbon composites are usually adopted in design. The recent progresses of research and application of ultra-high temperature materials in preparation, oxidation resistance, mechanical and physical characterization are summarized.
\end{abstract}

Key words hypersonic vehicle, high-temperature, thermal protection

Chinese Library Classification V250.1

2000 Mathematics Subject Classification $76 \mathrm{~K} 05$

\section{Introduction}

Hypersonic aircrafts, such as ballistic missiles, homing missiles, cruise missiles, reentry vehicles, trans-atmospheric vehicles and hypersonic airplanes, are a group of space vehicles, whose flight speed exceeds 5 Mach. Characterized by high maneuverability, long-distance and accurate destroy ability, hypersonic weapons have become the developmental direction of military equipments and will play an important role in the future war. Comparing with traditional weapons, hypersonic vehicles have many advantages, such as less response time, high ability of penetration, anti-defense and better viability of weapons ${ }^{[1]}$. Many countries, such as America, Russia, France, Germany, Japan and India, are devoted to improve hypersonic technology. Recently, many plans, such as Affordable Rapid Response Missile Demonstrator (ARRMD) plan made by Defense Advanced Research Projects Agency of America (DARPPA), HyTech plan by United States Air Force, Cool plan made by Russia, Prometheus plan made by France and ShyFE plan made by UK, have been made to encourage the research in this area. Supported by these plans, a lot of hypersonic aircrafts have been completed, such as AIM54C Phoenix missile (5 Ma), Fasthawk cruise missile (5 Ma). Now, new higher speed hypersonic aircrafts, whose flight speed exceeds $10 \mathrm{Mach}$, are being studied in some countries. With higher and higher 
flight speed, aircrafts' service environment is becoming worse and worse. Thermal protection system is playing more and more important role in aircrafts' safety. Thus, research of thermal protection structures and materials of hypersonic vehicles has been becoming more and more important.

\section{Large scale thermal protection materials}

Large scale thermal protection materials are used in aircrafts except the highest temperature areas. Ceramic tiles are traditionally used as large scale thermal protection materials. However, their brittleness, low damage resistance and high maintaining cost prevent the further application of these materials. Metallic thermal protection structures (TPS) is the main developmental direction of modern thermal protection systems.

\subsection{Structure design of TPS}

NASA Langley Research Center began to study metallic TPS supported by United X-20 plan $^{[2]}$ in the 1970s. From then on, metallic TPS configurations have been improved from early stand-off structure, multiwall structure, super alloy with honeycomb sandwich to ARMOR structure $^{[3-6]}$.

(1) Stand-off structure

The outer surface is comprised of wave metal panels and the inner core uses different configurations (shown as in Fig. 1), such as wave, strip, honeycomb and lattice structure. The thermal protection panel is fixed by fasteners at the outer surface edge. Insulations are placed in the space between the outer thermal protection panel and the inner structure. However, this thermal protection configuration has no moisturepro of function. 万方数据

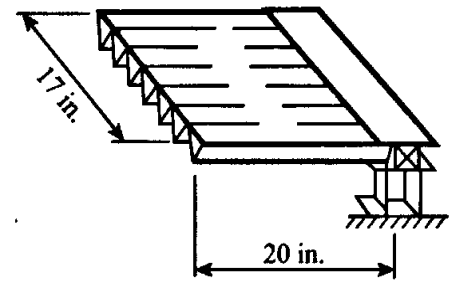

(a) Wave structure

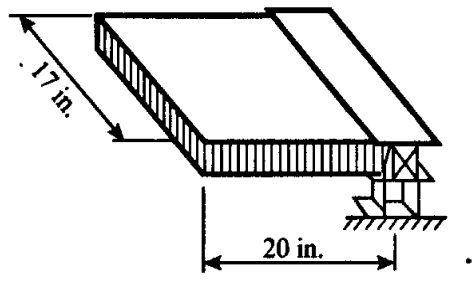

(c) Honeycomb structure

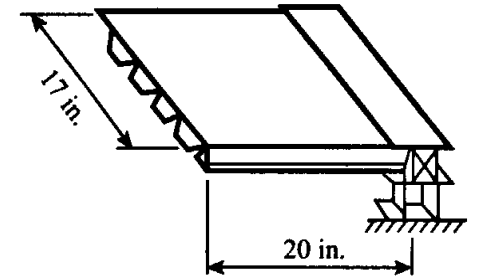

(b) Strip structure

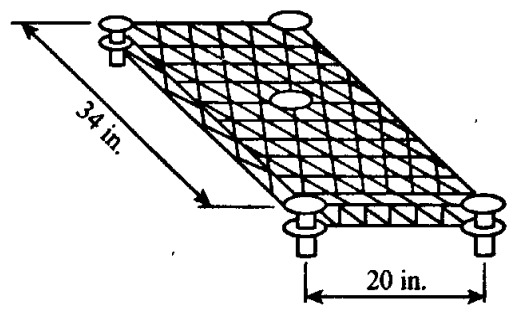

(d) Lattice structure

Fig. 1 Stand-off structure of TPS

(2) Multiwall structure of TPS

Multiwall structure of TPS consists of metal sheets and a honeycomb core. The metal sheets and a honeycomb core, which are made of titanium and nickel alloys, are connected through a special welding process (shown as Fig. 2). Compared with stand-off structure, titanium multiwall structure possesses better heat endurance. However, it has larger density and lower efficiency, especially at high temperatures. Hence, the inner titanium multiwall structure is replaced by the lightweight fibrous insulation. 


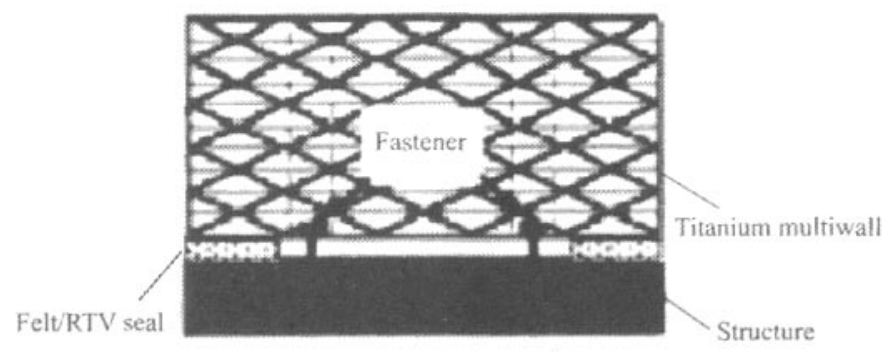

Fig. 2 Multiwall structure of TPS

(3) Super alloy with honeycomb sandwich

Super alloy with honeycomb sandwich consists of Cerrachrome and Q-fiber insulation, which forms higher and lower temperature insulation. The outer surface is comprised of a foil-gage Inconel 617 honeycomb sandwich and the inner surface is a titanium honeycomb sandwich with a part of one facesheet and the core removed to save weight (shown as Fig. 3). The improved honeycomb sandwich TPS uses lightweight fibrous insulation (Saffil insulation) and foil to further decrease its mass.

万方数据

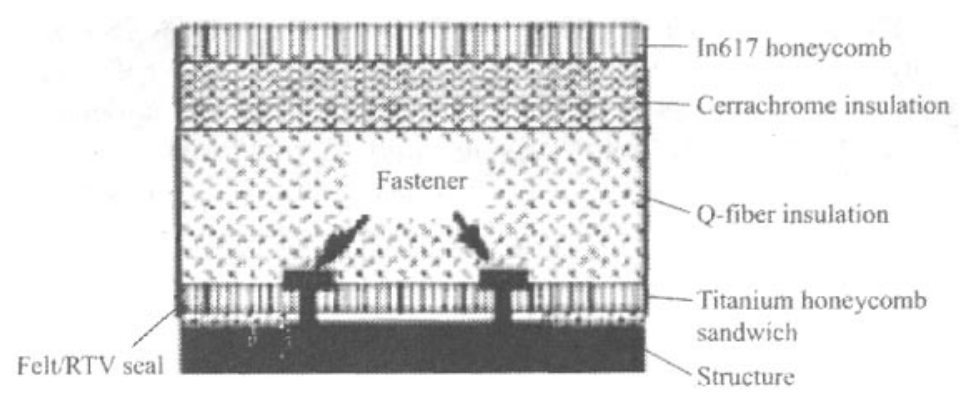

Fig. 3 Super alloy with honeycomb sandwich structure

(4) ARMOR thermal protection structures

ARMOR TPS is one of the important candidates for thermal protection systems. Each square panel is mechanically attached to a metallic, stand-off bracket at each corner, and stand-off bracket is made of Inconel 718. The novel stand-off bracket provides a way to release load between the outer hotter surface and the inner colder surface. It does not only avoid heat short, but also allows free thermal expansion for the outer surface. It is convenient to increase the thickness of Inconel 617 honeycomb sandwich panel in order to meet the ARMOR TPS strength request.

\subsection{Testing and Characterization of TPS}

Many researchers have finished experimental and theoretical studies about large scale thermal protection materials in the past years. Cunnington ${ }^{[7]}$ measured the effective thermal conduction coefficients of seven multi-layer insulation structures and set up a theoretical model. Keller ${ }^{[8]}$ studied the radiative heat transfer of multi-layer insulation structures by ignoring thermal conductivity of solids. Applying approximate heat flux method, Daryabeigi ${ }^{[9-13]}$ presented some computational models for analyzing the radiative heat transfer of multi-layer insulation structures. In order to solve the key issues of aircrafts, metal TPS with two functions (thermal protection and supporting mechanical loads) was performed by States Air Force of America. A 
series of experimental tests and analytical methods ${ }^{[14-23]}$ are being developed to characterize and improve metallic TPS. The tests included rain erosion tests, low-specd and hypervelocity impact tests, thermal vacuum TPS panel tests, arcjet TPS panel tests and acoustic TPS panel tests. Rain erosion flight tests on an F-15 aircraft were conducted by Rockwell International at NASA Dryden. A special fixture was designed to suspend TPS samples beneath an F-15 aircraft. The fixture provided eight rows of TPS samples. Each row had a sample at $0^{\circ}, 10^{\circ}$ and $20^{\circ}$ angle of attack. Therefore, eight TPS concepts could be tested at three different angles of attack, respectively. The primary purpose of the tests was to evaluate the rain erosion resistance of rigid ceramic tiles and flexible blankets. However, preoxidized Inconel 617 and titanium honeycomb sandwich samples were also tested. The metallic specimens were tested at a variety of conditions from light mist to very heavy rain at speeds up to 500 knots over the course of five test flights. Low-speed impact tests were performed on a variety of Inconel 617 and titanium honeycomb sandwich specimens using the low-speed impact facility at NASA LaRC (Figure 5 ). The facility features a dropped impactor which is used to measure the impact force profile. Interchangeable impact heads provide variable impact radii. A knife-edge support fixture can be simplified as supported boundary conditions for the 10-cm-square impact specimens. More than 30 metallic TPS specimens were tested at the light gas gun facility at NASA Marshall Space Flight Center (MSFC).

A special fixture was developed to hold honeycomb sandwich coupons, internal insulation, a coupon of titanium foil or honeycomb, and substructure panel to simulate a TPS panel attached to a substructure. Aluminum spheres from 0.125 to 0.25 diameters were fired at the specimens at $7 \mathrm{~km} / \mathrm{sec}$. The four panel array was tested in the arcjet at NASA Ames. The four TPS panels were mounted to a representative composite fluted core structural panel using bonded the数据 studs. Thermocouples were located at several locations under the sides of the panels in the gaps and on the substructure. An infrared thermal camera was used to observe the temperature distribution on the surface of the array. In addition, several analytical models were constructed to predict the thermal and structural behavior of superalloy honeycomb TPS. Detailed three-dimensional finite element and fiuite difference models were developed for the TPS panels. One-dimensional finite element heat transfer models were developed to predict complex thermal performance of fibrous and multilayer insulations as a function of temperature and pressure. A one dimensional TPS sizing code has been developed and enhanced to predict the thickness and the mass of a TPS required for a particular location on a vehicle.

\section{Ultrahigh temperature thermal protection materials}

Ultrahigh temperature thermal protection materials are used in the highest temperature areas of hypersonic aircrafts, such as cone and wing edges. Ultrahigh temperature thermal protection materials include refractory metals, ceramic composites, modified $\mathrm{C} / \mathrm{C}$ composites, etc. Due to high cost, hard machining, low oxidation resistance and large density, refractory metal is hard to be a candidate of thermal protection material for hypersonic vehicles. Ceramic composites and modified $\mathrm{C} / \mathrm{C}$ composites are the developmental trend of ultrahigh temperature thermal protection materials.

\section{$2.1 \mathrm{C} / \mathrm{C}$ composites}

$\mathrm{C} / \mathrm{C}$ composites are the combination of carbon rein with carbon fiber. Having excellent mechanical properties, such as high specific strength, high specific stiffness, small thermal expansion coefficient, good corrosion and heat shock resistance ability, $\mathrm{C} / \mathrm{C}$ composites are becoming an important ultrahigh temperature thermal protection material. There have been great improvements for $\mathrm{C} / \mathrm{C}$ composites in aviation and spaceflight field since $1958 . \mathrm{C} / \mathrm{C}$ composites are mainly used to make warhead components, aircraft thermal protection components and aero-engine hot end components ${ }^{[24,25]}$. Although $\mathrm{C} / \mathrm{C}$ composites have many advantages, it can not be used at high temperatures due to its oxidation above $500^{\circ} \mathrm{C}$ without any coating. 
The research work about $\mathrm{C} / \mathrm{C}$ composites is focused on how to promote oxidation resistance property and how to control coating failure. Walker ${ }^{[26]}$ presented the oxidation mechanism. There are two ways to promote oxidation resistance property of $\mathrm{C} / \mathrm{C}$ composites. One is by enhancing its own oxidation resistance, and while the other is by using oxidation coating. Matrix dipping and inhibitor can enhance its own oxidation resistance of $\mathrm{C} / \mathrm{C}$ composites. Some borides, such as $\mathrm{B}_{2} \mathrm{O}_{3}, \mathrm{~B}_{4} \mathrm{C}$ and $\mathrm{ZrB}_{2}$, are often used as inhibitors ${ }^{[27-32]}$. In recent years, oxidation-resistance coating techniques of $\mathrm{C} / \mathrm{C}$ composites have been improved greatly. Some new preparation methods ${ }^{[33-43]}$ of coatings, such as one-component coating, multi-component coating, composite coating, composite graded coating and precious metal coating have been put forward. The preparation methods of coating include CVD method, PACVD method, sol-gel method and liquid-phase method, etc. Heat stress occurs at the interface of coating and $\mathrm{C} / \mathrm{C}$ composites for thermophysical properties' difference. This leads crack extend and fall from coating. How to optimize coating structure to avoid the mismatch of matrix and $\mathrm{C} / \mathrm{C}$ composites is a key point ${ }^{[44]}$. Until now, there is still no $\mathrm{C} / \mathrm{C}$ composites, which can be used in air above $2000^{\circ} \mathrm{C}$ for long time.

\subsection{Ultrahigh temperature Ceramics}

Among the ultrahigh temperature ceramics (UHTCs) are a group of materials consisting of transition-metal compounds with high melting point, such as $\mathrm{ZrB}_{2}, \mathrm{TaC}, \mathrm{HfN}, \mathrm{HfB}_{2}, \mathrm{ZrC}$, etc. UHTCs have good chemical and physical stability at ultra-temperature conditions. The studies on UHTCs are focused on the oxidation behavior as well asstrengthening and toughening mechanisms. UHTCs were initially presented in the $1950 \mathrm{~s}^{[45]}$. Compositions with 5 to 50 vol.\% $\mathrm{SiC}$ were investigated for both $\mathrm{ZrB}_{2}$ and $\mathrm{HfB}_{2}$ over a wide range of test temperatures and pressures. $20 \mathrm{vol} . \%$ compositions were judged optimal for hypersonic vehicles after a series of ${ }^{2}$ efforts ${ }^{[46-50]}$ supported by the US Air Force. Additions of C improved thermal stress resistance, but were detrimental to oxidation resistance at all proportions. Shaffer ${ }^{[51]}$ evaluated the oxidation resistance of $\mathrm{ZrB}_{2}$ with additions of the disilicides of $\mathrm{Ta}, \mathrm{Nb}, \mathrm{W}, \mathrm{Mo}, \mathrm{Zr}$, $\mathrm{Mo}_{0.5} \mathrm{Ta}_{0.5}$, and $\mathrm{Mo}_{0.8} \mathrm{Ta}_{0.2}$, as well as $\mathrm{Zr}_{5} \mathrm{Si}_{3}$. Pastor and Meyer ${ }^{[52]}$ evaluated the oxidation resistance of $\mathrm{ZrB}_{2}$ with additions of $\mathrm{MSi}_{2}$ or $\mathrm{M}_{5} \mathrm{Si}_{3}$, where $\mathrm{M}$ is a transition metal $\mathrm{Zr}, \mathrm{Ta}, \mathrm{Cr}$, Mo, or W. On the basis of scale thickness measurements after oxidation testing for up to $100 \mathrm{~h}$ at 1200 and $1400^{\circ} \mathrm{C}$, the $\mathrm{ZrB}_{2}+15 \mathrm{wt} . \% \mathrm{CrSi}_{2}$ composition was found to be the most oxidation resistant. Lavrenko and coworkers ${ }^{[53-55]}$ reported that a $\mathrm{ZrB}_{2}+50 \mathrm{wt} . \% \mathrm{ZrSi}_{2}$ composition was more oxidation resistant than $\mathrm{MoSi}_{2}$ and $\mathrm{WSi}_{2}$, and could be used up to $1700^{\circ} \mathrm{C}$. Kuriakose and Margrave ${ }^{[56,57]}$ measured weight changes for $\mathrm{ZrB}_{2}$ over the temperature range of $945-1256^{\circ} \mathrm{C}$ and also reported parabolic oxidation kinetics. In addition to the diborides, other materials were investigated for potential hypersonic applications ${ }^{[58-61]}$. Materials based on $\mathrm{ZrC}$ and $\mathrm{HfC}$ were extensively studied, but were found to oxidize (nonprotectively) below $1800^{\circ} \mathrm{C}$, which eliminated them from consideration for the temperature cycling hypersonic applications. In the $1970 \mathrm{~s}$, many researches began to realize that $\mathrm{ZrB}_{2}$ and $\mathrm{HfB}_{2}$ compounds would become the best thermal protection materials which can withstand temperatures up to $2700^{\circ} \mathrm{C}^{[62]}$. In order to keep sharp cone and front wing edges in hypersonic aircraft flight, SHARP plan was performed. NASA Sandia developed $\mathrm{ZrB}_{2}$ and $\mathrm{HfB}_{2}$ compounds UHTCs, whose density is $98 \%$. NASA Ames Research Center compared the ablation resistance property of $\mathrm{C} / \mathrm{C}$ composites with that of $\mathrm{ZrB}_{2}$ ceramic. The result showed that the ablation mass of $\mathrm{C} / \mathrm{C}$ composites is 130 times larger than that of UHTCs in the same condition. NASA Lewis Research Center studied the oxidation and ablation behaviors of UHTCs in extreme condition. $\mathrm{ZrB}_{2}$ ceramic exhibited good oxidation resistance and thermal shock resistance properties in arc heated tunnel ablation tests. Only much thinner oxide formed when $\mathrm{ZrB}_{2}$ ceramic samples were oxidized at $1800^{\circ} \mathrm{C}$ for 300 seconds. Stanley ${ }^{[63]}$ examined three of UHTCs more representative of a propulsion environment, i.e., higher oxygen partial pressure and total pressure. Results of strength and fracture toughness measurements, furnace oxidation, and high velocity thermal shock exposures are presented for $\mathrm{ZrB}_{2}$ plus 20. vol.\% $\mathrm{SiC}$, $\mathrm{ZrB}_{2}$ plus 14 vol.\% $\mathrm{SiC}$ plus 30 vol.\% $\mathrm{C}$, and $\mathrm{SCS}-9 \mathrm{a}$ 
$\mathrm{SiC}$ fiber reinforced $\mathrm{ZrB}_{2}$ plus 20 vol.\% SiC. Monteverde ${ }^{[64]}$ investigated the resistance to oxidation in ambient air at a temperature up to $1600^{\circ} \mathrm{C}$ of two hot-pressed diborides matrix composites, both containing $19.5 \mathrm{vol} . \% \mathrm{SiC}$ and $3 \mathrm{vol} . \% \mathrm{HfN}$. The result showed that modest weight gains and limited corrosion depths highlighted a rather good thermal stability. Monteverde ${ }^{[65]}$ successfully produced ultrahigh temperature $\mathrm{HfB}_{2}-\mathrm{SiC}$ ceramics by reactive hot-pressing (RHP) and spark plasma sintering (SPS). The material processed by SPS retained its original strength and fracture toughness up to $1500^{\circ} \mathrm{C}$.

Another kind of UHTCs is $\mathrm{C} / \mathrm{SiC}$ composites, which possess many advantages, such as low density, high strength, high temperature endurance, good ablation and impact resistance. The oxidation resistance property of $\mathrm{C} / \mathrm{SiC}$ composites are better than that of $\mathrm{C} / \mathrm{C}$ composites. Oak Ridge Lab(America), SEP Co. (France) and Karslure University(German) began research works on $\mathrm{C} / \mathrm{SiC}$ composites in the $1980 \mathrm{~s}$. $\mathrm{C} / \mathrm{SiC}$ composites were used in the thermal protection structures of Hermes airship, Hotel and Sanger space shuttles. A novel C/SiC ceramic, which could work in oxidation atmosphere at $1650^{\circ} \mathrm{C}$, was developed by North western Polytechnical University. The bending strength at room temperature was above $700 \mathrm{MPa}$ and the fracture toughness was $19 \sim 20 \mathrm{MPa} \cdot \mathrm{m}^{1 / 2}$. The preparation methods of $\mathrm{C} / \mathrm{SiC}$ composites include $\mathrm{RMI}$ method, LPI method and CVI method. Bertrand ${ }^{[66]}$ developed two generations of multilayered interphases, composed of carbon and silicon carbide, which act as a mechanical fuse in $\mathrm{SiC} / \mathrm{SiC}$ composites with improved oxidation resistance. Examinations were then performed on the loaded samples and damaging mode characterized at nanometric scale. Macroscopic results for a $2.5 \mathrm{D} \mathrm{C} \mathrm{f}-\mathrm{SiC}$ composite creep tested in tension are presented by Boitier ${ }^{[67,68]}$. Dalmaz ${ }^{[69,70]}$ 陀新数据he characterisation of the elastic properties of a long-fibre-reinforced ceramic-matrix composite. Seven of the nine independent elastic constants of a woven $2.5 \mathrm{D}$ carbon-fibre reinforced $\mathrm{SiC}$ ceramic matrix have been measured by an ultrasonic technique associated with a numerical optimisation process. Halbig ${ }^{[71,72]}$ investigated oxidation behaviors of $\mathrm{C} / \mathrm{SiC}$ composites under a static tension load. Kiyoshis ${ }^{[33-75]}$ studied self-healing and roughness-enhancing of $\mathrm{C} / \mathrm{SiC}$ composites. Many research works ${ }^{[7,77]}$ were performed by North Western Polytechnical University

\section{Conclusions}

Thermal protection structures and materials of hypersonic vehicles is one of the key technologies in aircrafts' design and manufacture. It is a challenge task to develop thermal protection structures and materials for hypersonic vehicles because of the hostile service environment. A lot of notable progresses on manufacture methods, oxidation resistance methods, service environmental simulation, mechanical and physical properties' characterization of thermal protection materials have been made by ceaseless efforts. However, the existing thermal protection materials can not meet the requirements of new hypersonic vehicles with higher and higher speed. Especially, the thermal protection materials used in high temperature air condition for a long time should be deeply studied. The authors think some key research issues should be emphasized as follows:

(1) Air thermodynamic models and simulation methods;

(2) Test methods of thermal protection materials in aircraft service condition;

(3) Oxidation mechanism and micro-structure design of UHTCs;

(4) Methods of strengthening, toughening and thermal shock resistance of UHTCs;

(5) Integrative design of anti-oxidation/load-carrying/anti-thermo-cracking for thermal protection of structures and materials. 


\section{References}

[1] Moses Paul L, Rausch Vincent L, Nguyen Luat T, Hill Jeryl R. NASA hypersonic flight demonstrators-overview, status and future plans[J]. Acta Astronautica, 2004, 55(3/4):619-630.

[2] Jay Miller. The X-planes X-1 to X-29[J]. Specialty Sress, Marine on St Croix, MN, 1983, (4):10-13.

[3] Bohon H L, Shideler J L. Radioactive metallic thermal protection systems: a status report[J]. Journal of Spacecraft and Rockets, 1977, 12(10):626-631.

[4] Shideler J L, Kelly H N, Avery D E. Multiwall TPS-an emerging concept[J]. Journal of Spacecraft and Rockets, 1982, 19(4):7-8.

[5] Blair W, Meaney J E, Rosenthal H A. Fabrication of prepackaged super alloy honeycomb thermal protection system panels[R]. NASA-TP-3257, 1993, (3):5-7.

[6] Gorton M P, Shideler J L, Web G L. Static and aero thermal tests of a super alloy honeycomb prepackaged thermal protection system[R]. NASA-TP-3257, 1993, (3):2-3.

[7] Cunnington G R, Zierman C A. Performance of multi-layer insulation systems for temperatures to $700 \mathrm{~K}[\mathrm{R}]$. NASA CR-907, 1967210.

[8] Keller K, Hoffmann M , Zorner W , Blumenberg J. Application of high temperature multilayer insulations[J]. Acta Astronautica, 1992, 26(6):451-458.

[9] Kamran Daryabeigi. Thermal analysis and design of multi-layer insulation for reentry aerodynamic heating[R]. AIAA 2001-2834.

[10] Kamran Daryabeigi. Effective thermal conductivity of high temperature insulations for reusable launch vehicles[R]. NASA TM-1999-20892.

[11] Alan D. Sullins, Kam ran Daryabeigi. Effective thermal conductivity of high porosity open cell nickel foam[R]. AIAA 20012819.

[12] Kamran Daryabeigi. Heat transfer in high temperature fibrous insulation[R]. AIAA 2002-3332

[13] Kamran Daryabeigi. Analysis and testing of high temperature fibrous insulation for reusable launch vehicles[R]. AIAA 99-1044, 1999.

[14] Blosser M L. Development of metallic thermal protection systems for the reusable launch vehicle[R]. NASA Technical Memorandum $110296,1996$.

[15] Yao Caogen, Lii Hongjun, Jia Xinchao, Zhang Xuhu, Wang Qi. Development of metallic thermal protection system[J]. Aerospace Materials \& Technology, 2005, 35(2):10-13 (in Chinese).

[16] Xia Deshun. Review of metallic thermal protection system for the reusable launch vehicle[J]. Missiles and Space Vehicles, 2002, 256(2):21-26 (in Chinese).

[17] Guan Chunlong, $\mathrm{Li}$ Yao, He Xiaodong. Research status of structures and materials for reusable TPS[J]. Aerospace Materials \& Technology, 2003, 33(6):7 11 (in Chinese).

[18] Cao Yi, Cheng Haifeng, Xiao Jiayu, Li Yongqing. An introduction to american metallic TPS research work[J]. Aerospace Materials \& Technology, 2003, 33(3):9-12 (in Chinese).

[19] Han Jiecai, Chen Guiqing, Meng Songhe, Li Xiaohai. New-typed ARMOR thermal protection systems[J]. Journal of Astronautics, 2004, 25(3):350-353 (in Chinese).

[20] Zhao Ying. Development of launch vehicles in 2000[J]. Missiles and Space Vehicles, 2001, 249(1):16-22 (in Chinese).

[21] Myers D E, Martin C J, Blosser M L. Parametric weight comparison of current and proposed thermal protection system (TPS) concepts[C]. In: 33rd Thermophysics Conference, AIAA 933459, Norfolk, Virginia, 1999.

[22] Cowart K, Olds J. Integrating aeroheating and TPS into conceptual RLV design[C]. In: 9th International Space Planes and Hypersonic Systems and Technologies Conference, Norfolk, Virginia, 1999.

[23] Brewer W D, Bird Keith, Wallace Terryl, Sankaran S A. Alloys and coating development for metallic TPS for reusable launch vehicles[C]. In: 2000 National Space Missile Materials Symposium, San Diego, California, February 28-March 2, 2000.

[24] Buckley J D, Ediel D D. Carbon-carbon materials and composites[M]. New York: Noyes Publications, 1993. 
[25] Savage G. Carbon-carbon composites[M]. London: Chapman \& Hall, 1993, 198-209.

[26] ' Walker Jr P L. Carbon em dash an old but new material[J]. Carbon, 1972, 10(4):369-382.

[27] Lavruquere S, Elanchard H, Pailler R, et al. Enhancement of the oxidation resistance of interfacial area in $\mathrm{C} / \mathrm{C}$ composites. Part II. Oxidation resistance of B-C, Si-B-C and Si-C coated carbon preforms densified with carbon[J]. Journal of the European Ceramic Society, 2002, 22(7):10111021.

[28] Cui Hong, Su Junming, Li Ruizhen, Li Hejun, Kang Mokuang. On improving anti ablation property of multi matrix C/C to withstand $3700 \mathrm{~K}[\mathrm{~J}]$. Journal of Northwestern Polytechnical University, 2000, 18(4):669-673 (in Chinese).

[29] Yan Guishen, Wang Jun, Su Junming, Li Hejun, Hao Zhibiao. Influence of refractory carbides synthesized in the modification of matrix on the oxidation resistant performance of $\mathrm{C} / \mathrm{C}$ composite[J]. Carbon, 2003, 114(2):3-6 (in Chinese).

[30] Zhu Xiaoqi, Yang Zheng, Kang Mokuang, Zhang Haitau. Effect of matrix modification on the oxidation resistance of carbon/carbon composites[J]. Acta Materiae Compositae Sinica, 1994, 11(2):107-111 (in Chinese).

[31] Luo Ruiying, Li Dongsheng. A new way of enhancement of oxidation resistant properties for carbon/carbon composites[J]. Journal of Astronautics, 1998, 19(1):95-98 (in Chinese).

[32] Park Soo-jin, Soe Min-kang. The effects of $\mathrm{MoSi}_{2}$ on the oxidation behavior of carbon/carbon composites[J]. Carbon, 2001, 39:1229-1235.

[33] Jashi A, Lee J S. Coating with particulate dispersions for high temperature oxidation protection of carbon and C-C composites[J]. Composites A, 1997, 28(2): 181189.

[34] Cheng Laifei, Zhang Litong, Han Jintan. Preparation of Si-Mo oxidation protection coating for Cararon-carbon composites[J]. High Technology Letters, 1996, 6(4):17-20 (in Chinese).

[35] Cheng Laifei, Zhang Litong, Xu Yongdong, Zhou Wancheng. Structure of the oxide film on the siw coating for $\mathrm{C} / \mathrm{C}$ composites prepared by liquid reaction formation method[J]. Journal of the Chinese Ceramic Society, 1997, 25(5):537-541.

[36] Zeng Xierong, Li Hejun, Zhang Jianguo, Hou Yanhong, Yang Zheng. Effect of microstructure and component on oxidation resistance of $\mathrm{MoSi}_{2}-\mathrm{SiC}$ multilayer ceramic coating[3]. Acta Materiae Compositae Sinica, 2000, 17(2):42-45 (in Chinese).

[37] Huang Jianfeng, Zeng Xierong, $\mathrm{Li}$ Hejun, et al. $\mathrm{Al}_{2} \mathrm{O}_{3}$-mullite-SiC- $\mathrm{Al}_{4} \mathrm{SiC}_{4}$ multi-composition coating for carbon/carbon composites[J]. Materials Letters, 2004, 58(21):2627-2630.

[38] Huang Jianfeng, Zeng Xierong, Li Hejun, et al. $\mathrm{ZrO}_{2}-\mathrm{SiO}_{2}$ gradient multi-layer oxidation protective coating for $\mathrm{SiC}$ coated carbon/carbon composites[J]. Surface \& Coating Technology, 2005, $190(2 / 3): 255-259$.

[39] Cairo C A A, Graca M L A, Silva C R M, et al. Functionally gradient ceramic coating for carbon/carbon anti-oxidation protection[J]. Journal of European Ceramic Society, 2001, 21(3):325329.

[40] Buchanan F J, Little J A. Particulate containing glass sealants for carbon-carbon composites[J]. Carbon, 1996, 31(4):649 654.

[41] Strife J R. Ceramic coating for carbon-carbon composites[J]. Ceramic Bulletin, 1988, 67(2):369374.

[42] Wu Tsung-ming, Wu yung-rong. Methodology in exploring the oxidation behavior of carboncarbon composites[J]. Journal of Materials Science, 1994, 29(5):1260-1264.

[43] Westwood M E. Oxidation protection for carbon fiber composites[J]. Journal of Materials Science, 1996, 31(6): 13891397.

[44] Eckel A J, Bradt R C. Thermal expansion of laminated, woven, continuous ceramic fiber/chemicalvapor-infiltrated silicon carbide matrix composites[J]. Journal of American Ceramic Society, 1990, 73(5):1333-1338.

[45] Rudy E. Compendium of phase diagram data: ternary phase equilibria in transition metal-boroncarbon-silicon systems, part 5[M]. Air Force Materials Laboratory, Wright-Patterson Air Force Base, Ohio, 1969. 
[46] Kaufman L, Clougherty E V. Investigation of boride compounds for very high temperature applications[R]. RTD-TRD-N63-4096, Part III, Cambridge, MA: ManLabs Inc, March 1966.

[47] Clougherty E V, Kalish D, Peters E $\mathrm{T}$. Research and development of refractory oxidaton resistant diborides[R]. AFML-TR-68-190, Cambridge, MA: ManLabs Inc, 1968.

[48] Kaufman L, Nesor H. Stability characterization of refractory materials under high velocity atmospheric flight conditions[R]. Part III, Vol III, AFML-TR-69-84, Cambridge, MA: ManLabs Inc, 1970.

[49] Mcclaine L A. Thermodynamic and kinetic studies for a refractory materials program[R]. Report ASD/TDR/62/204, Part I, USA:Jan 1, 1962.

[50] Berkowitz-Mattuck J B. Kinetics of oxidation of refractory metals and alloys at $1000-2000^{\circ} \mathrm{C}[\mathrm{R}]$. Technical Report ASDTDR-62-203, AFML, WPAFB, OH, 1962/1963.

[51] Peter T B, Shaffer. An Oxidation resistant boride composition[J]. American Ceramic Society Bulletin, 1962, 41(2):96-99.

[52] Pastor H, Meyer R. Study of the effect of additions of silicides of some group IV-VI transition metals on sintering and high-temperature oxidation resistance of titanium and zirconium borides[J]. Revue Internationale des Hautes Tempe ratures et des Refractaires, 1974, 11(1):41-45.

[53] Lavrenko V A, Panasyuk A D, Protsenko T G, et al. High-temperature reactions of materials of the $\mathrm{ZrB} / / 2-\mathrm{ZrSi} / / 2$ system with oxygen[J]. Soviet Powder Metallurgy and Metal, 1982, 21(6):471 473.

[54] Mcclaine L A. Thermodynamic,Kinetic. Studies for a refractory materials program[R]. Report ASD/TDR/62/204, Part II,USA:April, 1963.

[55] Brown F H. Stability of titanium diboride and zirconium diboride in air, oxygen, and nitrogen progress report[R]. Progress Report No 20-252, Jet Propulsion Laboratory, Pasadena, CA, 25 Feb 1955.

万(56数攵据riakose A K, Margrave J L. The oxidation kinetics of zirconium diboride and zirconium carbide at high temperatures[J]. J Electrochem Soc, 1964, 111(7):827-831.

[57] Mcclaine L A. Thermodynamic and kinetic studies for a refractory materials program[R]. Report ASD/TDR/62/204, Part III, USA:Jan, 1964.

[58] Clougherty E V, Peters E T, Kalish D. Diboride materials $[\mathrm{J}]$. Candidates for Aerospace Applications, 1969, 35(15):297-308.

[59] Kaufman L. Boride composite-a new generation of nose cap and leading edge materials for reuseable lifting re-entry systems[C]. In: Proceedings of AIAA Advanced Space Transportation Meeting, AIAA Paper 70-278, NY, 1970.

[60] Buckley J D. Static, subsonic, and supersonic oxidation of JT graphite co mposites[R]. Technical Report NASA TN D-4231, NASA, Wash D C, Oct. 1967.

[61] Rao G A Rama, Venugopal V. Kinetics and mechanism of the oxidation of $\mathrm{ZrC}[\mathrm{J}]$. Journal of Alloys and Compounds, 1994, 206(2):237-242.

[62] Fenter J R. Refractory diborides as engineering materials[J]. SAMPE Quart, 1971, 2(3):1-15.

[63] Levinea Stanley R, Opilab Elizabeth J, Halbigc Michael C, Kisera James D, Singhd Mrityunjay, Salema Jonathan A. Evaluation of ultra-high temperature ceramics for aeropropulsion use[J]. Journal of the European Ceramic Society, 2002, 22(14/15):2757-2767.

[64] Monteverde. The thermal stability in air of hot-pressed diboride matrix composites for uses at ultra-high temperatures[J]. Corrosion Science, 2005, 47(8): 2020-2033.

[65] Monteverde. Progress in the fabrication of ultra-high-temperature ceramics:'in situ' synthesis, microstructure and properties of a reactive hot-pressed $\mathrm{HfB}_{2}-\mathrm{SiC}$ composite $[\mathrm{J}]$. Composites Science and Technology, 2005, 65(11/12):1869-1879.

[66] Bertrand $\mathrm{S}$, Droillard C, Pailler $\mathrm{R}$, et al. TEM structure of $(\mathrm{PyC} / \mathrm{SiC}) \mathrm{n}$ mutilayered interphases in $\mathrm{SiC} / \mathrm{SiC}$ composites[J]. Journal of the European Ceramic Scoiety, 2002, 20(1):1-13.

[67] Boitier G, Vicens $\mathrm{J}$, Chermant $\mathrm{J}$ L. Understanding the creep behavior of a 2.5D Cf-SiC composite:morphology and microstructure of the as-received material[J]. Materials Science and Engineering, 2000, 279(1/2):73-80.

[68] Boitier G, Chermant J L, Vicens J. Understanding the creep behavior of a 2.5D Cf-SiC composite II: experimental specifications and macroscopic mechanical creep responses[J]. Materials Science and Engineering, 2000, 289(1):265-275. 
[69] Dalmaz A, Ducretd P, Guerjouma R E, et al. Elastic moduli of a 2.5D Cf/SiC composite[J]. Experimental and Theoretical Estimates Composites Science and Technology, 2000, 60(6):913925.

[70] Dalmaz A, Ducretd P, Rouby D, et al. Mechanical behavior and damage development during cyclic fatigue at high-temperature of a $2.5 \mathrm{D} \mathrm{C} / \mathrm{SiC}$ composite[J]. Composites Science and Technology, 1998, 58(5):693-699.

[71] Halbig M C, Brewer D N, Eckel A J, et al. Stressed oxidation of C/SiC composites[R]. NASA/TM 219972107457, New York: NASA, 1997.

[72] Halbig M C, Brewer D N, Eckel A J. Degradation of continuous fiber ceramic matrix composites under constant loaded conditions[R]. TM 220002209681, New York: NASA, 2000.

[73] James M S, Larry P Z. Performance of four ceramic matrix composite divergent flap inserts following ground testing on an F110 turbofan engine[J]. Journal of the American Ceramic Society, 2000, 83(7):1727-1738.

[74] Kiyoshi S, Hiroki M, Osamu F, et al. Developing interfacial carbon-boron-silicon coatings for silicon nitride-fiber reinforced composites for improved oxidation resistance $[\mathrm{J}]$. Journal of the American Ceramic Society, 2002, 85(7):1815-1822.

[75] Schulte J F, Schmidt J , Tamme R, et al. Oxidation behaviour of C/C-SiC coated with SiCB4C-SiC cordierite oxidation protection system[J]. Materials Science and Engineering A, 2004, 386(1/2):428-434.

[76] Zhang Litong, Cheng Laifei, Xu Yongdong. Progress in research work of new CMC-SiC[J]. Aeronautical Manufacturing Technology, 2003, (1):24-32 (in Chinese).

[77] Zhang Litong, Cheng Laifei. Discussion on strategies of sustainable development of continuous fiber reinforced ceramic matrix composites[J]. Acta Materiae Compositae Sinica, 2007, 24(2):1-6 万方数据hinese). 